\title{
Effects of milling process sequence on the residual stress related monolithic components deformation
}

\author{
Xiaoming Huang \\ Mechatronics Engineering Department, Binzhou University, Binzhou 256600, China \\ Key Laboratory of High Efficiency and Clean Mechanical Manufacture of Ministry of Education, School of \\ Mechanical Engineering, Shandong University, Jinan 250061, China
}

Keywords: Milling process sequence, residual stress, monolithic components.

\begin{abstract}
Machining deformation of aircraft monolithic component is one of the most serious problems that the aircraft manufacturing industry had to face. The effects of milling process sequence on multi-frame monolithic components deformation are studied, and the inherent frequency of the multi-frame beam at different machining process is also investigated. Based on the analysis of milling process characters, some control stratagems could be developed to reduce the deformation of thin wall component due to residual stress in the blank. In order to study the effect of blank initial residual stress on components deformation, chemical milling is used to remove the machining induced residual stress on the machined surface of the components. The research results show that the initial residual stress in the blank is the main factor of deformation for 3-frame monolithic beam, and the coupling action of the initial residual stress and machining induced residual stresses aggravate the deformation.
\end{abstract}

\section{Introduction}

The components used in the aerospace industry are usually thin wall structures. Because of their poor stiffness, thin-walled workpieces are very easy to deform under the acting of residual stresses in the blank and machining induced residual stress ${ }^{1-3}$. With the increasing trend of monolithic components for large size aircraft parts, quality control of a machined part is becoming increasingly critical for satisfying the demands of superior reliability.

Residual stress was the root cause of aircraft monolithic components deformation. Some researches show that pre-stretching technology was one of the effective methods to reduce the initial residual stress in the blank. However, it is difficult to eliminate the initial stress ${ }^{4,5}$. Machining induced residual stress is produced on the machined surface of the workpiece due to the action of machining. Many researchers have attempted to study the deformation theory and control methods of thin components ${ }^{6-9}$. Although numerous studies have been conducted on the deformation of thin wall parts, the impact of decreasing workpiece rigidity (due to material removal) was not considered in the reported works. In the previous studies ${ }^{8,10}$, machining loads were often used to replace the machining induced residual stresses, and initial residual stresses were ignored. This assumption was harebrained to the actual situation.

Therefore, there is a strong need for the study of residual stress and milling process sequence on the monolithic components deformation, which helps to improve the final machined part quality by simulating the entire machining process. In the paper, the deformation and inherent frequency were compared to research the influences of the milling process sequence on the deformation performance. And the cause and main effect element of machining deformation of thin-walled component are explored. High-speed milling and chemical milling experiments were used to study the effect of machining induced residual stress and blank initial residual stress for deformation 


\section{Results}

In order to simplify the experiment and simulation approach against real part deformation, an exemplary analogy part is designed based on a real aircraft structural component as shown in Figure 1. It is a 3-frame monolithic beam that is $512 \mathrm{~mm}$ long, $50 \mathrm{~mm}$ wide and $30 \mathrm{~mm}$ thick. The three frames are named as A, B and C in the part. The lengths of the frames are $150 \mathrm{~mm}, 250 \mathrm{~mm}$ and $100 \mathrm{~mm}$. the thickness of the ribs and floors are $3 \mathrm{~mm}$.

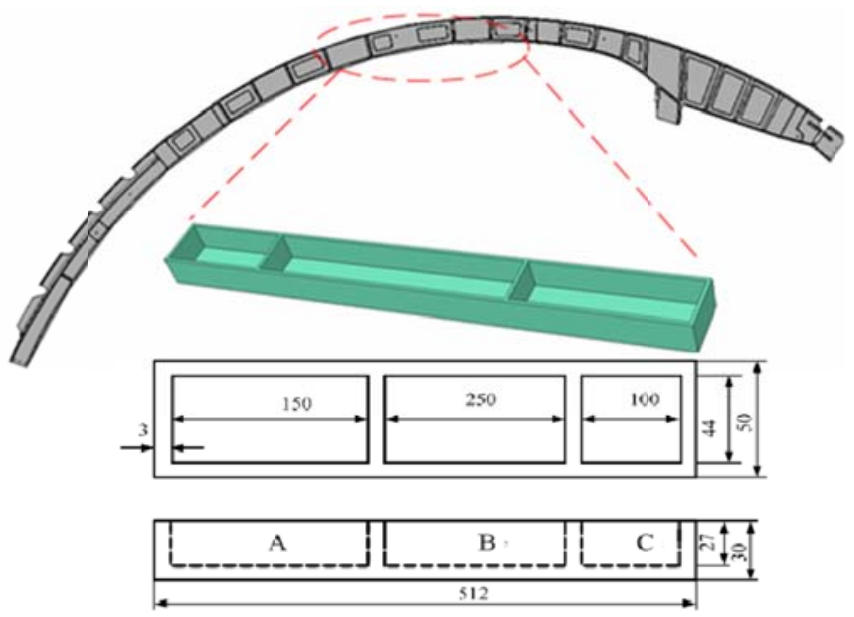

Figure1 | The structure of 3-frame monolithic components beam

The frames are machined one by one in the machining process. There are six kinds of milling process sequences according to the geometry characteristics of the parts showed in Figure 1. Three conditions are chosen to study the influence of the milling process sequences on deformation of the components. Mingling sequence(1) : A-B-C; Mingling sequence(2) : C-A-B; Mingling sequence(3) : B-C-A. Each frame manufacturing process is set as a step, the third manufacturing process step stands for final state of the parts.

By the superposition of initial residual stresses and milling induced stresses, combined deformation effects can be determined. Figure 2 shows the finite element simulation results of machining distortion of machining sequence (2). As can be seen from this graph, aluminum alloy aircraft monolithic component appears concave and bending distortion. After machining operation, due to the release and redistribution of residual stresses, the distortion of workpiece is caused, the law of which is bending distortion in the middle and warped at both ends. The maximum distortion values of process sequence (1), (2), and (3) are $0.308 \mathrm{~mm}, 0.298 \mathrm{~mm}$, and $0.329 \mathrm{~mm}$.
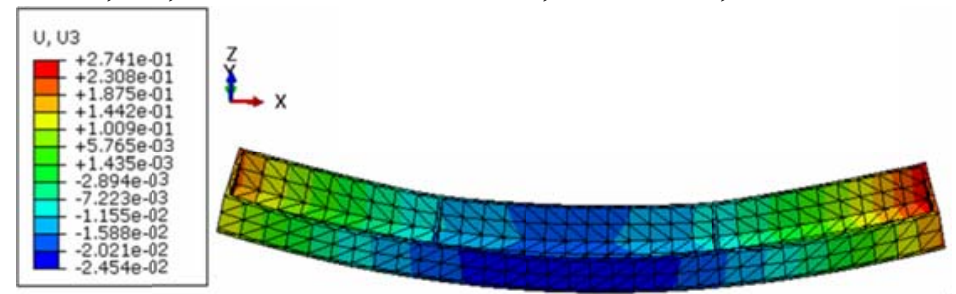

Figure 2 | Simulation result of machining distortion

The effect of initial residual stress or milling induced stresses on the deformation can be calculated by applying the residual stress separately. The milling process sequence (2) is used.

When the deformation is caused by blank initial residual stress only, the max deflection was in the middle of the component and the maximum deformation value is $0.249 \mathrm{~mm}$. The action of machining induced residual stress only causes very little machining deformation. The maximum deformation value is $0.0311 \mathrm{~mm}$. Taking into account the coupling action of initial residual stress and machining induced residual stress, the maximum deformation position appears around the middle of the component, and the maximum deformation value is $0.298 \mathrm{~mm}$, which is larger than the deformation value only considering the effect of machining induced residual stress, but close to the deformation value only considering the effect of blank initial residual stress.

To verify finite element simulation results, machining distortion experiment for aluminum alloy aircraft monolithic beam is performed on a CNC machining center. 
The distortion values of 3-frame beam are listed in Figure 3. As can be seen from above Figure 3, the machining distortion law from finite element simulation is in accord with experiment results, which appears bending distortion in the middle and warps at both ends. Moreover, finite element simulation and experiment have the same maximum bending distortion position. Based on the above comparisons and analyses, the finite element simulation result agrees well with the experiment results.

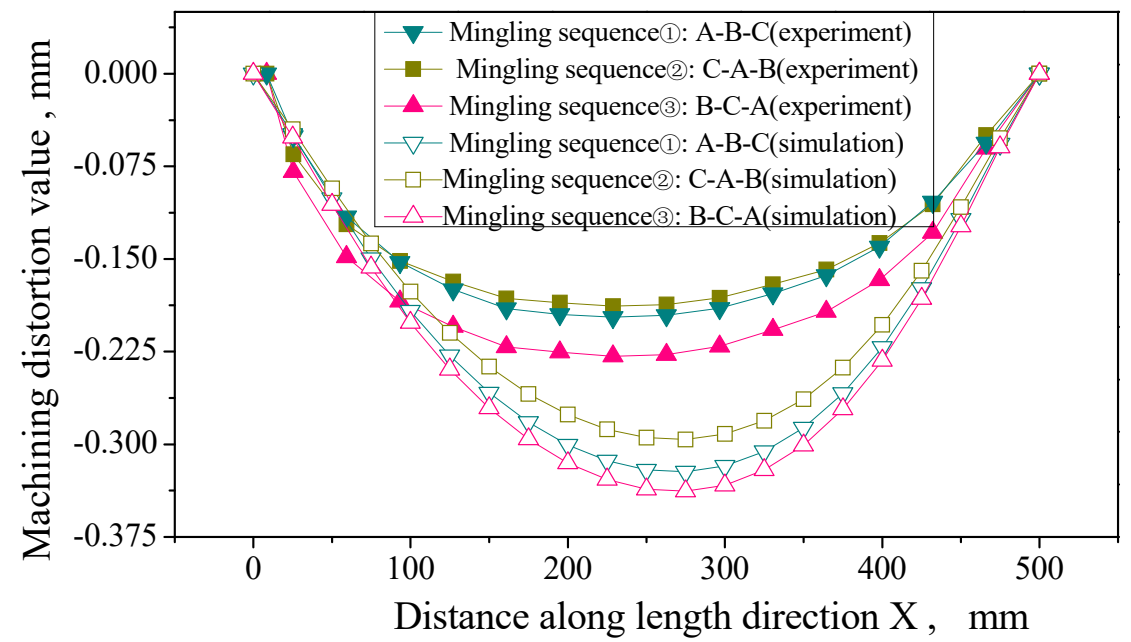

Figure 3 | Machining distortion curve of different milling process sequence

In order to verify the effect of initial residual stress on the deformation, chemical milling method was used to remove the milling induced residual stress. The maximum simulation deformation value and measurement value are compared and listed in Table 1. Based on the comparisons, it is shown that the machining deformation results from finite element simulation agree with the experiment results.

Table 1 | Comparison of the maximum FEM and measurement deformation values

\begin{tabular}{cccccc}
\hline \multirow{2}{*}{ Effect factor } & \multicolumn{2}{c}{ Initial residual stress } & \multicolumn{2}{c}{ Machining induced residual } & \multicolumn{2}{c}{\begin{tabular}{c} 
Coupling \\
action of \\
two \\
\cline { 2 - 5 }
\end{tabular}} & Deformation(mm) & percentage & Deformation(mm) & percentage & $\begin{array}{c}\text { factors(mm) } \\
\text { form }\end{array}$ \\
FEM & 0.249 & $83.5 \%$ & 0.0311 & $10.4 \%$ & 0.298 \\
Experiment & 0.165 & $88.2 \%$ & - & - & 0.187 \\
\hline
\end{tabular}

According to the above finite element simulation and experiment studies, some conclusions can be drawn that the initial residual stress is the main effect element of machining deformation for aircraft monolithic component, which plays an important role in machining deformation. The deformation caused by machining residual stress accounts for about $10 \%$ of the total deformation of the component, and the deformation caused by the blank initial residual stress accounted for $90 \%$ of the total deformation of the component. When large amount of material is removed, the equilibration of initial residual stresses is broken, and the residual stresses are redistributed to re-equilibrate it, which cause machining deformation for aircraft monolithic component.

\section{Discussion}

Through the comparison the correlation of milling processing schedule (material removed schedule) and the deformation results, different milling process schedule would produce analogous deformation styles and different deformation values. Sides frame first and middle frame last milling process sequence could produce smaller deformation.

When large amount of materials are removed, the equilibration of residual stresses are broken. And machining induced residual stresses are introduced on the surface of the components. To re-equilibrate them, the residual stresses are redistributed and cause machining deformation. 
Based on Euler-Bernoulli beam theory, the higher the stiffness, the greater the beam inherent frequency. Modal frequency analysis of the established 3D finite element model of machining process is carried out by the ABAQUS, and the first five natural frequencies are obtained.

The first five inherent frequencies of each machining step for different milling process sequence ware listed in Table 2. The first mode inherent frequency of the blank rectangular solid is $897.6 \mathrm{~Hz}$, and it decreases to $521.7 \mathrm{~Hz}$ for the final thin wall 3 -frame beam, about $41.8 \%$ drop.

Table 2 | Inherent frequency in the machining process of three sequence

\begin{tabular}{ccccccc}
\hline \multirow{2}{*}{$\begin{array}{c}\text { Machining } \\
\text { sequence }\end{array}$} & \multirow{2}{*}{ Step } & \multicolumn{5}{c}{ Inherent frequency $(\mathrm{Hz})$} \\
\cline { 3 - 7 } & & Mode 1 & Mode 2 & Mode 3 & Mode 4 & Mode 5 \\
\hline Initial State & 0 & 897.6 & 1355.4 & 1975.8 & 2737.8 & 3580.5 \\
\hline \multirow{2}{*}{ Sequence (1) } & 1 & 801.3 & 1189.1 & 1784.2 & 2543.4 & 3107.2 \\
& 2 & 630.3 & 1092.7 & 1544.9 & 1722.4 & 2647.3 \\
\hline \multirow{2}{*}{ Sequence (2) } & 1 & 856.1 & 1355.4 & 1912.7 & 2684.1 & 3315.1 \\
& 2 & 820.1 & 1256.2 & 1841.7 & 2565.8 & 3216.5 \\
\hline \multirow{2}{*}{ Sequence (3) } & 1 & 624.3 & 1082.7 & 1582.6 & 1760.7 & 2615.0 \\
& 2 & 542.4 & 954.6 & 1572.1 & 1725.8 & 2545.5 \\
\hline Final state & 3 & 521.7 & 920.1 & 1529.3 & 1683.8 & 2484.1 \\
\hline
\end{tabular}

As shown in the Figure 4, the inherent frequencies of the parts are diminished gradually with machining process. It decreases linearly as machining step rises at milling process sequence $(1)$. At milling process sequence (2), the inherent frequency of the processing step 1 and step 2 are $856.1 \mathrm{~Hz}$ and $820.1 \mathrm{~Hz}$ small, a drop about $4.5 \%$. It shows a clear decline from $820.1 \mathrm{~Hz}$ to $521.7 \mathrm{~Hz}$, with machining step from 2 to 3 , a drop of $36.7 \%$. When the materials are removed according to the milling sequence (3), the inherent frequency of the parts are $624.3 \mathrm{~Hz}, 542.4 \mathrm{~Hz}$ and $521.7 \mathrm{~Hz}$ at machining step 1, 2 and 3, the rate of descent are 30.4\%, 13.1\% and 4\%.

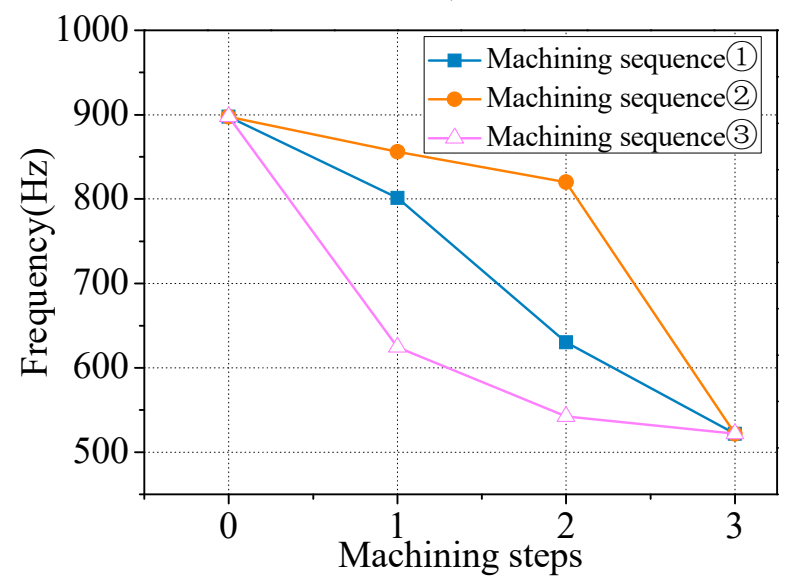

Figure 4 | Inherent frequency of mode 1 in the three machining sequence

This means that the material removal of the middle frame produces greater reduction on stiffness of the parts than both side frames. Selecting machining process sequence(2), machining of the frame in the middle is the last step, could make the most use of the stiffness of the component. It is available to reduce the deformation.

Based on the inherent frequency analysis, the material removal of the middle frame reduces the stiffness of parts seriously. Making full use of the stiffness variation in the process of machining is an optimized strategy of decreasing the deformation of aircraft monolithic component.

The initial residual stress in the blank is the main factor of deformation for monolithic component, and the coupling action of the initial residual stress and machining induced residual stresses aggravate the deformation. The deformation caused by machining residual stress accounts for about $10 \%$ of the total deformation of the component, and the deformation caused by the blank initial residual stress accounts for $90 \%$ of the total deformation of the component. 
Because the finite element simulation of machining distortion did not take into account the effect of cutting loads (including cutting force and temperature), therefore, the differences between FEM and the experiment mainly came from the simplification of acting mode of cutting loads.

\section{Methods}

FEM Simulation. In order to get the initial residual stress profile, crack-compliance method is used to measure the original residual stress. Figure 5a shows the initial residual stress distribution profile along thickness direction in the blank ${ }^{11}$. Milling induced residual stresses can be attributed to mechanical and thermal loads, which occurs between the workpiece and tool during the machining process. The machining induced residual stresses on the surface and subsurface of the workpiece are measured using X-ray diffraction technique and electro-polishing technology ${ }^{12}$, which is shown in Figure 5b.
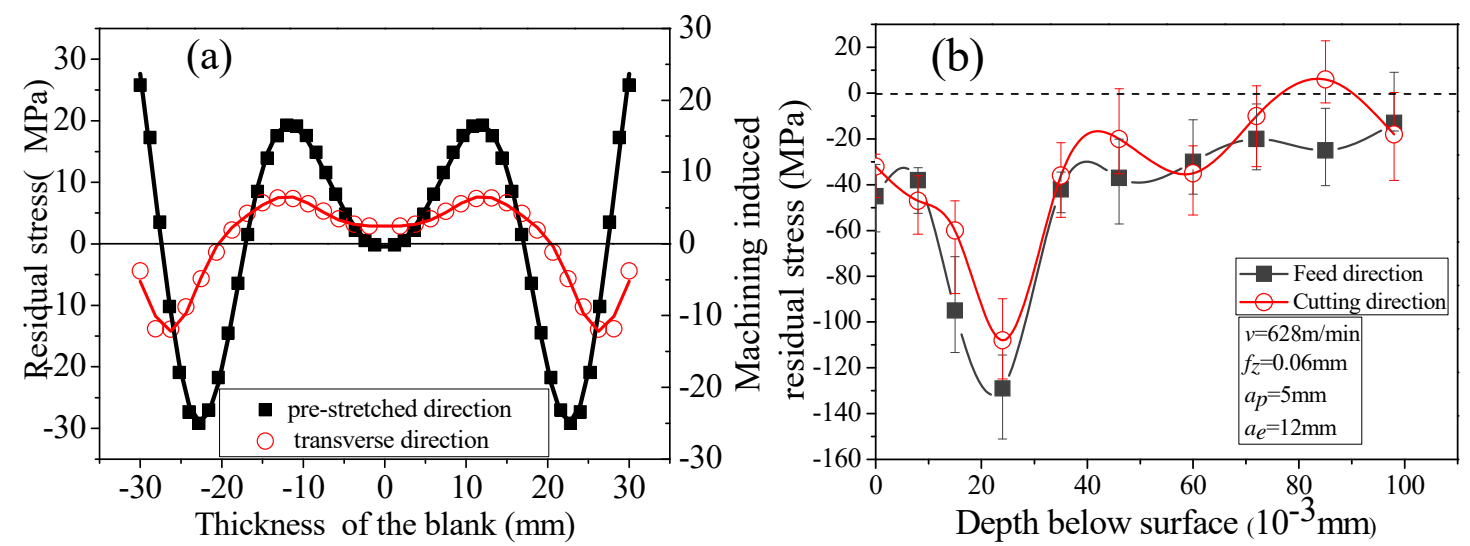

Figure 5 | Residual stresses profiles of 7050-T7451 plate. (a) initial residual stresses profile (b) machining induced

Finite element simulation of machining distortion is performed using the commercial finite element software ABAQUS. The subroutine (SIGINI) is used to introduce the stress condition. According to stress distribution characteristics, the multi-peak Gaussian functions are used to fit the residual stress curves. The technology of "element birth and death" was used to simulate the material remove process in the software. The 3-2-1 constraint principle is adopted as the boundary conditions, where the rigid motion of the workpiece is constrained, but the workpiece can be free to distort to reach a new stress equilibrium state. The removed elements of A, B, C frame are set as three sets, which are removed as a machining step when machining process simulation are carried out.

Experiment Verification. During machining, workpiece sides are nipped by jaw vice. The cutting parameters used in experiment are: the spindle rotation speed of $1000 \mathrm{r} / \mathrm{min}$, the $0.1 \mathrm{~mm}$ feed per tooth, the $4 \mathrm{~mm}$ radial cutting width, and the $6 \mathrm{~mm}$ depth of cutting. The solid carbide end mill whose diameter was $20 \mathrm{~mm}$ is adopted. The experiment set-up and the 3-frame monolithic components are illustrated in Figure 6. The distortion values of characteristic points of machined workpiece are measured using 3D coordinate-measure-machine MISTRAL 775. Some characteristic points along the length direction are picked up at intervals. 

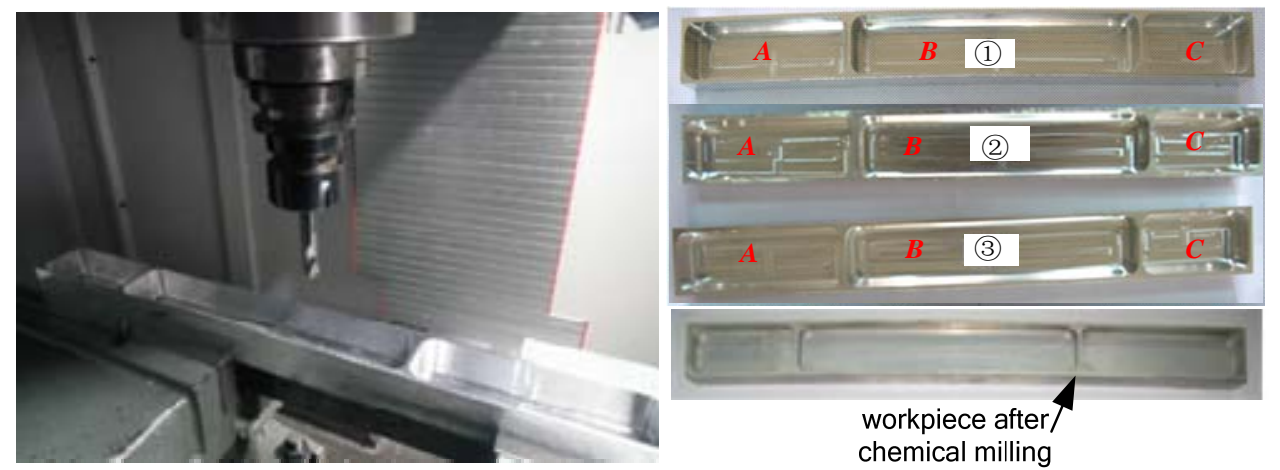

Figure 6 | Experimental set-up and 3-frame monolithic components

\section{Acknowledgements}

The authors want to thank for the support from the National Natural Science Foundation of China (No. 51275277).

\section{References}

[1] Megson, T. H.G. Aircraft structures for engineering students. Leeds University, UK, (2012).

[2] Izamshah, R., Mo, J. P. T. \& Ding, S. Hybrid deflection prediction on machining thin-wall monolithic aerospace components. J. Eng. Manuf. 203, 687-698 (2011).

[3] He, N. et al. Finite element method analysis and control stratagem for machining deformation of thin walled components. J. Mater. Process. Technol. 139, 332-336 (2003).

[4] Tang, Z. T. et al. Measuring residual stresses depth profile in pre-stretched aluminum alloy plate using crack compliance method. Chin. J. Nonf. Metals. 17, 1404-1409 (2007).

[5] Zhang, L. et al. FEM simulation and experimental study on the quenching residual stress of aluminum alloy 2024. Proc. Inst Mech Eng, Part B J. Eng. Manuf. 227, 954-964 (2013).

[6] Sun, J. et al. Key technology on processing deformation control and correctionof aviation overall parts. Aero. Manuf. Technol. 23, 62-66 (2009).

[7] Smith, S. R. et al. Sacrificial structure preforms for thin part machining. CIRP. Annals-Manuf. Technol. 61, 379-382 (2012).

[8] Jitender, K. \& Rai, P. X. Finite element method based machining simulation environment for analyzing part errors induced during milling of thin-walled components. Int. J. Mach. Tools. Manuf. 48, 629-643 (2008).

[9] Sun, J., Ke, Y. L. Study on machining distortion of unitization airframe due to residual stress. Chin. J. Mech. Eng. 41, 117-122 (2005).

[10]Guo, H. et al. Prediction on milling distortion for aero-multi-frame parts. Mater. Sci. Eng A. 499 230-233 (2009).

[11]Michael, B.P. \& Michael, R, H, Residual stress, stress relief and inhomogeneity in aluminum plate. Scripta. Mater. 46,77-82 (2002).

[12]Huang, X M. et al. An experimental investigation of residual stresses in high-speed end milling 7050-T7451 aluminum alloy. Adv. Mech. Eng. Article ID 592659 (2013).

\section{Author contributions}

Jie Sun designed the experiment. Xiaoming Huang performed simulation and analysis. Jie Sun and Xiaoming Huang wrote the paper. All authors contributed to analysis the experimental data and revision of the article.

\section{Additional information}

Supplementary information accompanies this paper at http://www.nature.com/ scientific reports Competing financial interests: The authors declare no competing financial interests. 